\title{
Düzağaç (Kozan-Adana) Bölgesindeki Bitümlü Şeyllerin Hümik Asit Özellikleri
}

\author{
Humic Acid Properties of Bituminous Shales in the Region of Düzağaç (Kozan-Adana)
}

\author{
Faruk AY $^{1}$, Ergün KASAKA ${ }^{2}$

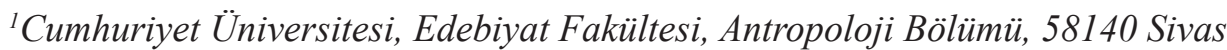 \\ (e-posta:farukay@cumhuriyet.edu.tr) \\ ${ }^{2}$ Cumhuriyet Üniversitesi, Fen Fakültesi, Biyoloji Bölümü, 58140 SİVAS
}

\begin{abstract}
ÖZ
Ülkemizde bitümlü şeyller kömür, petrol ve doğal gaz gibi fosil enerji kaynaklarıyla karşılaştırıldığında rezerv bakımından kömürden sonra ikinci sırada yer almaktadır ve bu nedenle de ülkemiz ekonomisi için önemli bir değere sahiptir. Tüm dünyada da olduğu gibi Türkiye'nin de en önemli sorunlardan birisi enerji ihtiyacının karşılanmasıdır. Ülkemizde enerji potansiyeli olan en önemli fosil yakıt kaynaklarından linyit ve taşkömürüne günümüze kadar nispeten gerekli önem verilmiş olmasına karşın, bitümlü şeyl için bunu söylemek mümkün değildir. Son yıllarda yapılan birçok bilimsel araştırmaya göre bitümlü şeyllerin enerji kaynağı olarak kullanılması yanı sıra farklı alanlarda da kullanılabileceği sonucuna varılmıştır. Bu alanlardan biri de tarımsal verimliliğin arttırılmasına yönelik çalışmalardır. Ülkemiz tarım topraklarının büyük çoğunluğunda, organik madde miktarının \% 1'in altında olması nedeniyle verimli ve kaliteli ürün yetiştirebilmek için toprak için ilave besin, yani organik maddeye ihtiyacı vardır. Bu çalışmada şeylerin enerji kaynăğ olarak kullanımı dışında, toprakların verimini arttırma potansiyeli değerlendirmeye çalışılmıştır. Bu kapsamda Düzağaç (Kozan-Adana) bitümlü şeyllerinin toprak güçlendirici (organik gübrehümik Asit) olarak kullanım imkanları araştırılmıştır. Düzağaç bitümlerinin pH'1 7.79 olarak belirlenmiş olup, bu değer asidik topraklarımızın pH'ının dengelenmesine yardımcı olacaktır. Ülkemizde var olan ancak enerji kaynağı olarak kullanımı ekonomik olmayan bitümlü şeyllerin organik gübre (Hümik Asit) olarak kullanılmasının ekonomik açıdan ve topraklarımızın ıslahı ve geleceği için büyük önem taşıdığı sonucuna varılmıştır.
\end{abstract}

Anahtar Kelimeler: Adana-Kozan, bitümlü şeyl, Düzağaç, hümik asit, organik gübre

\begin{abstract}
Bituminous shale in our country takes second place in terms of reserve, when compared the fossil energy resources such as coal, petroleum and natural gas and for this reason, it appears that they have an important
\end{abstract}


value for the country economy. One of the biggest problems in our country, like in all over the world, is to meet the energy demand. Although lignite and coal from the most important fossil fuels having energy potential in our country have been considered important until today, it is not possible to say this for the bituminous shale. According to many scientific studies carried out in recent years, bituminous shale can be used both energy resource and different areas. One of these areas is the efforts to increase agricultural productivity. In the vast majority in our country's agricultural lands, due to below $1 \%$ of organic matter amount, there is a need for organic matter additives such as fertilizers to obtain efficient and high quality products. In this study, it has been tried to assess the potential of shale to increase the efficiency of soils, rather than as an energy source. In this context, possibility of use of Düzağaç (Kozan-Adana) bituminous shale as a soil conditioner (compost-humic acid) has been investigated. pH of Düzağaç bitumen was defined as 7.79 and this value will help our acidic soils to be balanced in terms of pH. In this study, it was concluded that the use of bituminous shale, which has not economic value as an energy source in our country, as compost (humic acid) is crucial to economical ways and our soil's reclamation and future.

Key words: Adana-Kozan, bituminous shale, compost, Düzağaç, humic acid

\section{GíRiş}

Bitümlü şeyller; organik çözücülerde çözünmeyen ve "kerojen" olarak tanımlanan organik madde içeren, ince taneli ve genellikle laminalı yapıya sahip sedimanter kayaç olarak tanımlanmakta olup, aynı zamanda bileşiminde yüksek oranda mineral maddeler de içermektedir. Bitümlü şeylin inorganik ve organik olmak üzere iki ana bileşeni vardır. İnorganik bileşenler (mineraller) çökelme koşulları hakkında önemli bilgiler sunar ve genellikle kuvars, kil, karbonat, sülfid, sülfat, zeolit ve evaporit minerallerinden oluşmaktadır. (Şengüler, 2007; WEC, 2007). Organik bileşenler (maseraller) ise çökelme ortamı yanında bitümlü şeylin kalitesine yönelik önemli bilgiler sunar. Bitüm şeylerin içerisinde bulunan bitüm oranı da kalitesi açısından önemlidir; örneğin ülkemizdeki bitümlü şeyl sahalarının genellikle bitüm oranları \%5-6 arasında görülmekte iken en yüksek oran Himmetoğlu sahasında \%43 civarındadır (Kök, 2006; Güleç ve Önen, 1993).

Dünyanın birçok alanında ticari ölçekte yıllardır şeyl petrolü üretiminden sonra üzerinde en çok araştırma yapılan kullanım alanı termik santrallerde kat1 yakıt olarak değerlendirilme potansiyelidir. Estonya'da tüketilen enerjinin yaklaşı $\% 60$ '1 bitümlü şeyllerden karşılanmaktadır. Kukersit tipi yüksek kaliteli bitümlü şeyllerden Estonya'da elektrik, gaz, s1v1 hidrokarbon ve diğer kimyasal ürünlerin üretiminde yararlanılmakta olup, bu prosesler sonucunda açığa çıkan artık şeyl ürünü ise çimento hammaddesi olarak değerlendirilmektedir. Almanya'da Dotternhausen'de kurulmuş olan Rohrbach prosesinde bitümlü şeyl yakılarak elektrik enerjisi elde edilmekte ve artık şeyller ise çimento hammaddesi üretiminde kullanılmaktadır (Şengüler, 1985; Ballice, 1995; Probstein ve Hicks, 1982). Bu kullanım alanları dışında özellikle 1964 y1lından bu yana asidik toprakların güçlendirilmesi amacı ile de bitümlü şeyllerden yararlanılmaktadır (Şengüler, 1994). Bitümlü şeyllerin bileşiminde bulunan inorganik maddeler, çökelim koşulları, iklim, çökelim ortamının kimyasal özellikleri ve alterasyon hakkında bilgiler vermesi yanı sıra, toprak için gerekli olan birçok elementi doğal olarak içermesi nedeniyle toprak güçlendirici olarak kullanılmasını sağlamaktadır.

Normal şartlarda bir bitkinin gelişimi için toprakta her elementin yeterli miktarda bulunması gerekmektedir. Ülkemiz topraklarının organik madde içeriği yönünden çok fakir olması, bitki gelişimi için gerekli maddelerin iklimsel koşullar, yanlış tarım uygulamaları ve artan 
bilinçsiz kimyasal gübre kullanımı beraberinde toprak tuzluluğu, toprağın strüktürünün bozulması, toprakta bazı elementlerin birikmesi ve bu birikimin diğer besin maddeleri aleyhine gelişmesinin yanında toprak ve su kaynakları üzerine önemli derecede kirletici etkilerinin olmas1 gibi nedenlerden dolayı zamanla azalmıştır (Taban, 2012). sonucunda ülkemizde suni (kimyasal) gübre tüketimi FAO (2009) verilerine göre 2002 y1lında $127.27 \mathrm{~kg} \mathrm{ha}^{-1}$ (hektar başına kilogram) iken 2007 y1lında ise $183.28 \mathrm{~kg} \mathrm{ha}^{-1}$ seviyelerine kadar artmıştır. Yoğun kimyasal gübreleme ile toprak organik maddelerce fakirleşmekte, dolayısıyla biyolojik faaliyet azalması toprağın yapısının bozulmasını da beraberinde getirmektedir. Yoğun kimyasal gübreleme nedeniyle toprakta organik madde miktarı, dolayısıyla humus oranı ve biyolojik aktivite azalıp, verilen gübreler toprakta tutunamadığı için yıkanıp gidecektir. Bitki besin elementlerinin, bitkilerin alabileceği şekle dönüşümleri de durduğu için toprağın fiziksel ve kimyasal özellikleri tarım açısından olumsuz olarak etkilenecektir. Bu durum da topraklarımızda tuz konsantrasyonunun yükselmesine, mikroorganizma faaliyetlerinin azalmasına, yeraltı suyunun kirlenmesine, kimyasal olarak verilen gübrelerin topraktan çabucak yıkanmasına, verim ve elde edilen ürünün kalitesinin düşmesine ve erozyonla toprak kaybına neden olacaktır (Kural, 1978). Organik gübre kullanılması halinde ise, bu durum tamamen tersine dönmeye başlayacak ve giderek topraklarımızın içerdiği organik madde miktarı artabilecektir. Ayrıca, üretilen organik gübre bitkinin ihtiyacı olan mineral maddeleri absorblayarak, bitkinin ihtiyaç duyduğu anda bitkiye verebilecek ve mineral maddelerin de taşınmasını engelleyebilecektir.

Ülkemizdeki tarım topraklarının \% 21.47 'sinde organik madde miktar $\% 1$ 'in altında, $\%$ 43.78'inde \% 1-2 arasinda, \% 22.62'sinde $\%$ 2-3, \%7.57'sinde \% 3-4 ve \% 4.56'sinda ise \%4'den büyük olarak belirlenmiştir (Çolakoğlu, 1996; Eyüpoğlu, 1999; Depel, 2000). Ülkemiz topraklarının çoğunluğunda organik madde miktarının oldukça düşük olması nedeniyle bitümlü şeyllerin tarım sektöründe kullanılmasına yönelik araştırmalar da gündeme gelmiştir.

Bu çalışmada da Adana-Kozan (Düzağaç) civarında bulunan bitümlü şeyllerin tarımsal alanlardaki organik gübre kullanım potansiyeli değerlendirilmiştir (Şekil 1).

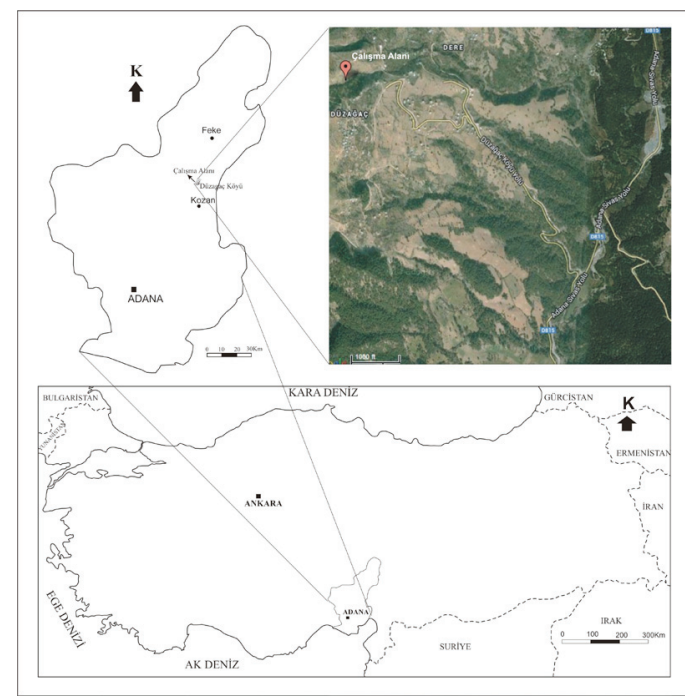

Şekil 1. Çalışma alanının yer bulduru haritası.

Figure 1. Location map of study area. 


\section{Stratigrafi}

İnceleme alanı, Toridler (Ketin, 1966) tektonik birliği içerisinde yer almaktadır. Toroslar, Alp Orojenik Kuşağının Anadolu'nun güney ve doğu kesimlerinden geçen önemli bir bölümünü oluşturmaktadır. Bölgede, Geyik Dağı Birliği, Aladağ Birliği ve Bozkır Birliği olmak üzere baslıca üç tektono-stratigrafik birlik yer almaktadır (Özgül ve Kozlu, 2002; Özgül, 2006).

İnceleme alanı içerisinde bulunan birimler, ilk kez Özgül (1976) tarafından tanımlanmış ve Geyik Dağı Birliği’ne dahil edilmişlerdir (Özgül, 1971; 1976). Doğu Toroslar'da Adana kuzeyinde Kozan, Feke, Saimbeyli, Tufanbeyli, Develi ve Pınarbaşı ilçeleri arasında geniş alan kaplayan Geyik Dağı Birliği, bu yörede Kambriyen'den Tersiyer'e değin uzanan zaman aralığında çökelmiş, baslıca şelf tipi karbonat ve kırıntılı kayaları kapsamaktadır (Özgül vd., 1973; Metin vd., 1984). Birliğin taban seviyelerinde meta kırıntılılardan oluşan Alt Kambriyen yaşlı Emirgazi Grubu (Özgül vd., 1973) yer alır. Grup altta, volkanit ara katk1lı, yer yer moloz akması çökelleri içeren Alt Kambriyen yaşlı Kozan Formasyonu ve başlica kuvarsitlerden oluşan, Alt Kambriyen yaşlı Koçyazı Kuvarsiti tarafından uyumsuzlukla üzerleyen formasyonlardan oluşmaktadır. Değirmentaş Formasyonu (Dağlığlu, 1988; 1990) alttan üste doğru dolomit-dolomitik kireçtaşı, neritik kireçtaşı ve ince şeyl ara katkıl1, yumrulu görünüşlü kireçtaş1 düzeylerini kapsamakta olup, Orta Kambriyen yaşlıdır (Demirtaşl1, 1967). Başlıca kumtaş1-şeyl ardalanmasından oluşan Alt Ordovisiyen yaşı (Özgül vd., 1973) Armutludere Formasyonu (Demirtaşl1, 1967), Değirmentaş Kireçtaşı'nı uyumlu ve geçişli olarak üzerlemektedir. Alt Devoniyen yaşlı Ayı Tepesi Formasyonu ise
(Özgül vd. 1973), başlıca neritik karbonatlardan (dolomit, kireçtaşı) oluşmaktadır Alt düzeylerinde stromatolit ara katk1lı dolomitler, üst kesimleri mikritik kireçtaşından oluşan Şafaktepe Kireçtaşı (Demirtaşl1, 1967), Ayı Tepesi Formasyonu'nu uyumlu olarak üzerlemektedir. Özellikle alt düzeylerinde bol brachiopod ve mercan içeren birim Orta Devoniyen yaşlıdır (Özgül vd. 1973). Üst Devoniyen yaşlı Gümüşali Formasyonu (Demirtaşl1, 1967; Özgül vd. 1973) ise başlıca şeyl, kumtaşı, biyohermal ve biyostromal kireçtaşının düzensiz ardalanmasından oluşur.

İncelenen bitümlü şeyllerin de içinde bulunduğu Ziyarettepe Formasyonu (Demirtaşl1, 1967), kumlu kireçtaşı ve kireçli kumtaşı ara katmanlı, koyu renkli şeyl düzeyi ile başlar. Bol organik maddeli ve Turnesiyen'i temsil eden brachiopodlar içeren bu düzeyin üzerinde kuvarsarenit, daha üstte ise Viziyen'i temsil eden fosil topluluğu belirlenen kireçtaşı düzeyleri yer alır. Yiğıltepe Formasyonu (Demirtaşl1, 1967), başlica platform tipi neritik karbonatlardan oluşmaktadır. Şeyl ara katkıları içeren formasyon, en altta kalınlıkta kuvarsit düzeyi ile başlar ve kireçtaşı istifi Üst Permiyen'i temsil eden fosil topluluğu içerir. Alt Triyas yaşlı Katarası Formasyonu (Demirtaşlı, 1967), başlıca şeyl ara katkılı neritik kireçtaşı ve killi kireçtaşından oluşur. Jura-Kretase yaşlı Köroğlu Tepesi Kireçtaşı, altta dolomit düzeyi ile başlar; daha üstte bol algli ve bentonik foraminiferli, dolomit ve stromatolitli kireçtaşı ara düzeylerini kapsayan kireçtaşı istifi yer alır. Köroğlu Tepesi Kireçtaşı; Yı̆̆ıltepe, ve Katarası Formasyonlarını, doğrudan açısız uyumsuzlukla üstler. Metin vd. (1982) tarafindan isimlendirilen Miyosen yaşlı Sümbüldağ1 Formasyonu, kalın kumtaşı-marnçamurtaşı istifi ile konglomera ve kireçtaşlarından oluşmuştur. (Şekil 2 ve 3). 


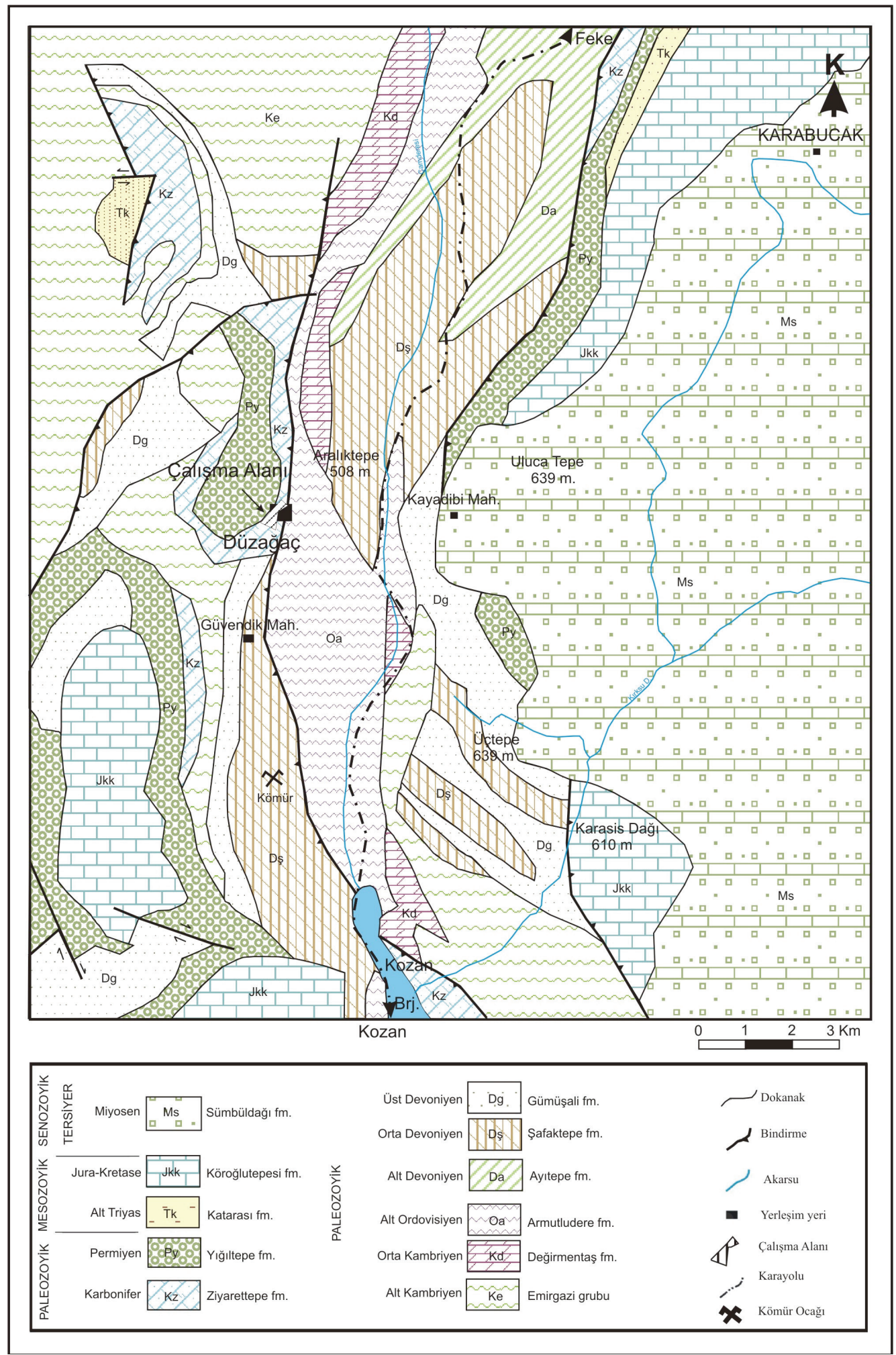

Şekil 2. Çalışma alanının ve yakın çevresinin jeoloji haritası (Ayhan, 1988; Yapıcı ve Anıl, 2007'den değiştirilerek). Figure 2. Geological map of study area and its vicinity (modified from Ayhan, 1988; Yapıcı and Anıl, 2007). 


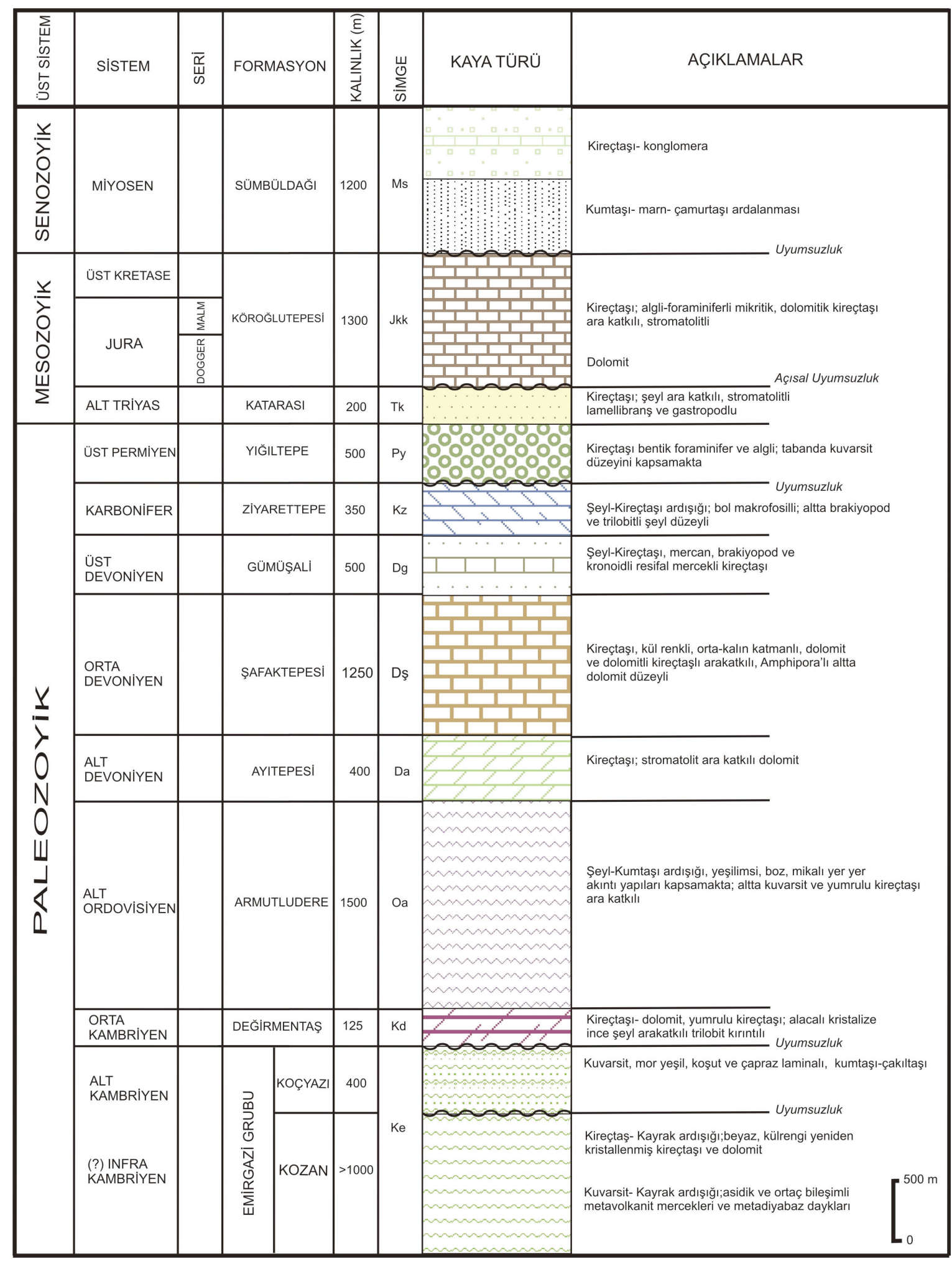

Şekil 3. İnceleme alanının genelleştirilmiş stratigrafik dikme kesiti (Özgül ve Kozlu, 2002'den değiştirilerek).

Figure 3. A generalized Stratigraphic section of study area (modified from Özgül and Kozlu, 2002). 


\section{Bitümlü şeyl oluşum ve özellikleri}

Bitki ve hayvansal organizmalara ait kalıntılarının deniz ve göllerde birikimi, farkl1 jeolojik devirler ve fiziko-kimyasal reaksiyonlar geçirmesi sonucu oluşan sedimanter organik maddelerin çok az bir kısmı organik çözücüler içerisinde çözünebilmektedir. Sedimanter kayaçlarda bulunan ve çözülebilen bu bileşim bitüm, çözülemeyen organik maddeler ise kerojen olarak adlandırılır (Tissot ve Welte, 1984). Bitümlü şeyl; kerojence zengin, ince taneli ve genellikle laminalı (yapraksı) bir yapıya sahip ve jeolojik olaylar sonucu oluşmuş sedimanter bir kayaçtır. Kerojen içermesi nedeniyle bitümlü şeyller kömür benzeri bir tür enerji kaynağı olarak da tanımlanır (Ünalan, 2003). Genellikle literatürde "petrollü şeyl" (oil shale) olan, 1sıtıldığında petrol ve gaz üretilebilen bu organik kayaçlar, bitümlü şist (bituminous schist) veya bitümlü şeyl (bituminous shale) olarak da adlandırılmaktadır.

Sentetik "şeyl petrolü" ise bu kayaçlardan ancak isısal ve kimyasal işlemler sonucu elde edilebilmektedir. Bitümlü şeyl oluşumunu sağlayacak başlangıç maddelerinin türü ve bu maddelerin geçirdiği evreler, meydana gelecek şeylin renk, şeyl petrolü verimi gibi özelliklerini doğrudan etkilemektedir (Probstein ve Hicks, 1982). Organik yapıda büyük oranda liptinit maseralleri bulunmakta, bu durum ise bitümlü şeyl oluşumunu sağlayan karasal bitkiler, deniz ve göllerde yaşayan organizmaların lipit bakımından zengin olmalarından kaynaklanmaktadır. Kömürün yapısında bulunan vitrinit ve inertinit grubu maseraller bitümlü şeyllerin türüne bağlı olarak farklı oranlarda görülebilmektedir (Ballice vd. 1995). Bitümlü şeyllerin çökelim ortamlar1; büyük göller, sığ denizler ve bataklıklar ile ilgili göl ve lagünlerdir (Toraman ve Uçurum, 2009).

Bitümlü şeyller, dünyanın çeşitli bölgelerinde yaygın olarak bulunmaktadır. Dünyadaki bitümlü şeyl rezervi 300-550 milyar ton arasında değişmekte olup dünyadaki toplam bitümlü şeyl rezervinin \%62-72'si (213 milyar ton) ise Amerika Birleşik Devletleri'ne aittir (Örneğin, ABD'nin doğusundaki DevonianMissisipian'de bulunan bitümlü şeyller, 647.000 km'lik bir alana yayılmıştır). Brezilya ve Rusya'da yer alan rezervler eklendiğinde ise bu oran \%86'ya ulaşmaktadır (EASAC Report, 2007). Çizelge 1'de ülkelerin bitümlü şeyl rezervleri görülmektedir (Laherrere, 2005; USA Department of Energy, 2004).

Ülkemizde ise; Beypazarı (Ankara), Seyitömer (Kütahya), Hatıldağ (Bolu), Himmetoğlu (Göynük-Bolu), Mengen (Bolu), Ulukışla (Niğde), Bahçecik (Kocaeli), Burhaniye (Balıkesir), Beydili (Ankara), Dodurga (Çorum) ve Çeltek (Amasya) gibi sahalarda bulunmakta olup (Şekil 4) 1.64 milyar tonluk bir rezerv belirlenmiştir (Şekil 4). Ayrıca, Boyalı (Kastamonu), Demirci (Manisa), Ilıs1lik (Çankırı) ve Aspiras (Kastamonu) sahalarında da MTA tarafından prospeksiyon çalışmaları gerçekleştirilmiştir (Şengüler, 2007). 


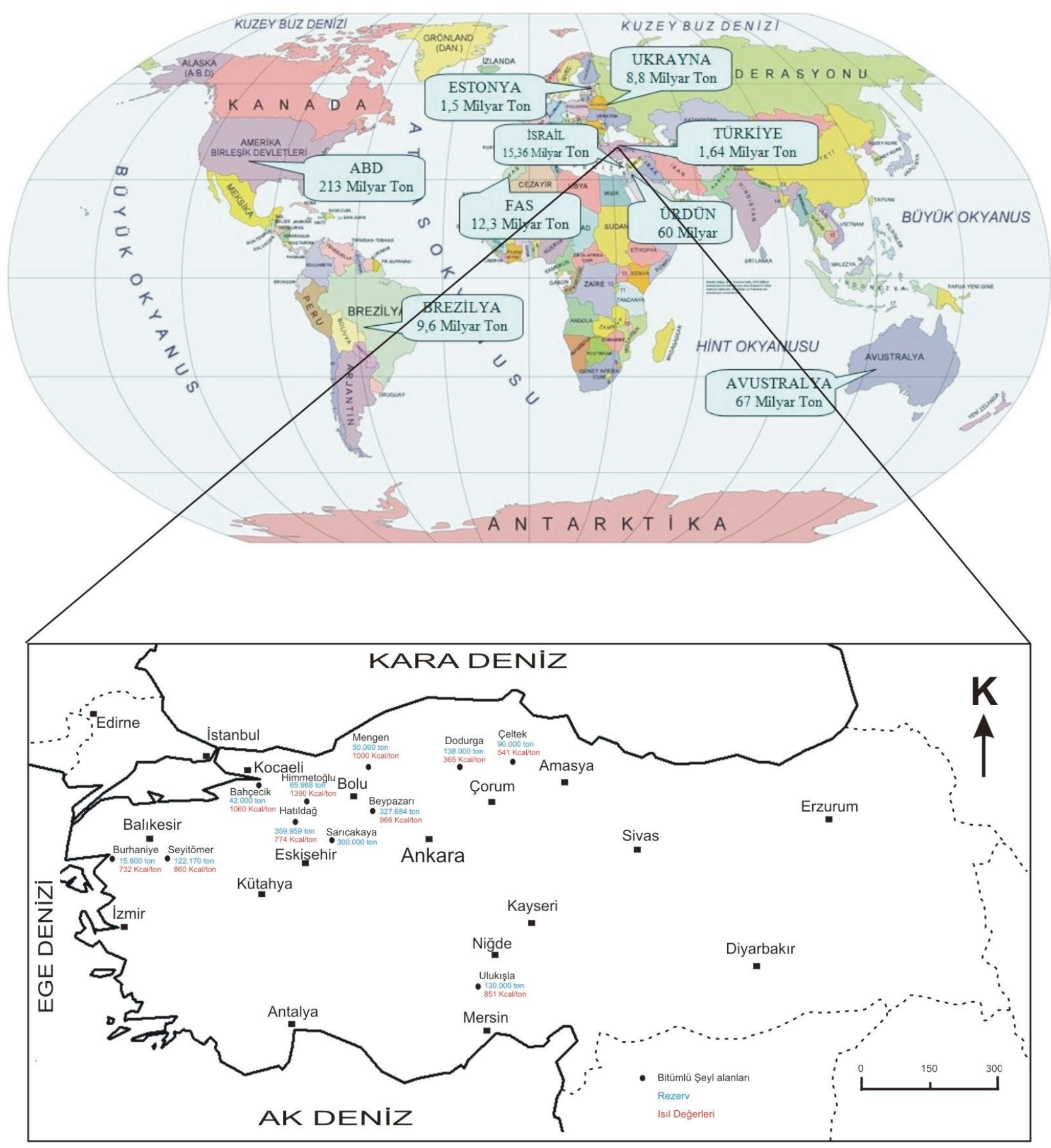

Şekil 4. Dünya'daki ve Türkiye'deki bitümlü şeyl alanları, rezerv ve 1sıl değerleri (Şengüler, 1994; 2001; Laherrere, 2005).

Figure 4. Butimunous shale regions, reserves and calorific values in the World and Turkey (Şengüler, 1994; 2001; Laherrere, 2005). 
Türkiye'deki bitümlü şeyllerin kalorifik değeri $1000 \mathrm{kcal} / \mathrm{kg}$ civarında veya bunun biraz daha altında olup, kül oranları ise yüksektir (Şekil 4). Üretim yöntemi olarak, toplam rezervin küçük bir bölümü açık işletme, geri kalanı ise derinlerde olduğu için yeraltı işletmeciliğine uygundur (DPT, 2001).

\section{Bitümlü şeyllerin organik gübre (hümik asit) Potansiyeli}

Hümik asitler veya humus, kısmen veya tamamı çürümüş bitki veya hayvan artıklarının oluşturduğu siyah veya koyu kahverenkli maddelerdir. 1841'de Von Liebig tarafindan "alkali ortamda kolayca çözünebilen, fakat suda çözünmeyen, alkalilerin veya asitlerin aksiyonu ile bitkilerin bozulması nedeniyle oluşan kahverenkli bir madde" olarak tanımlamıştır (Kural, 1998). Khristeva, humusu "zamanla bozunmaya karş1 maddenin ilk hayati durumundan daha dirençli k1lan hayvansal ve bitkisel organizmalardan arta kalan transformasyon maddesidir" olarak tanımlamıştır (Senn ve Kingman, 1973). Humus kelimesi bazı toprak bilimcileri tarafından "toprak organik maddesi" şeklinde de kullanılmıştır. $\mathrm{Bu}$ anlam topraktaki hümik asitleri içeren tüm organik maddeleri kapsamaktadır. Toprak organik madde kavramı genellikle bitki ve hayvan dokuları, toprak biyokütlesi, hümik maddeler ve canlı organizmalar tarafindan sentezlenmiş tüm organik maddeleri içermektedir. Hümik asitler kolloidal maddelerdir ve kil gibi hareket etmektedirler. Hümik molekülünün katyon değişim siteleri hidrojen iyonu ile doldurulduğu zaman oluşan madde "hümik asit" olarak düşünülmektedir (Senn ve Kingman, 1973). Fakat bunun $\mathrm{pH}$ üzerinde fazla etkisi yoktur. Zira, bu asit suda çözünmemektedir. Katyon değişim siteleri hidrojen haricinde herhangi bir katyon ile doldurulursa bu madde "humat" olarak tarif edilmektedir (Hayes vd., 1989). Kimyasal olarak bulunduğu bölgeye göre çok farklı özellikler gösteren hümik asitlerin moleküler büyüklüğü
2000-300000 Dalton, karbon içeriği \% 45-65, oksijen içeriği \% 30-50, katyon değişim kapasitesi 500-1500 meq/100 g olarak belirlenmiştir (Kim, 2003; Vogel vd., 1999).

Hümik asit ile ilgili ilk çalışmalar 1919'da Oden tarafından başlatılmış ve o zamandan bu yana $\mathrm{NaOH}$ ile yapilan ekstraksiyon metodu geniş çapta kabul edilen, uygulanan bir metod olarak tanımlanmıştır. Günümüzde Oden'in orjinal ekstraksiyon prosedürü temel olarak aynıdır, fakat yeni modern standartlara uyum sağlaması için bazı değişiklikler yapılmıştır (Kural, 1978). $\mathrm{NaOH}$, toprakta bulunan ve nicel olarak izole edilebilen hümik maddedeki en etkiliyici ayıraçtır. Saflaştırma prosesi sırasında da kolayca çıkartılması oldukça avantajdır. Günümüze kadar pek çok yerli ve yabancı araştırmacı değişik metotlarla hümik asit saflaştırma yöntemi kullanmıştır (Calemma ve Rausa, 1988; Dekker ve Cronje, 1991; Valdrighi vd., 1996; Detroit ve Lebo, 1997; Lehtonen vd., 2001; Francioso vd., 2003; Grabowska ve Gryglewicz, 2005; Lguriate vd., 2005; Skhonde vd., 2006). Bu çalışmada ise Lehtonen vd., (2001) tarafindan hazırlanan metod kullanılmıştır.

\section{ANALIZZ YÖNTEMI}

\section{Hümik Asitlerin Ayrıştırılması}

Düzağaç bitümlü şeyllerinden alınan yüzey örnekleri C.Ü. Jeoloji Mühendisliği kırma öğütme laboratuar'ında Fritisch Marka çeneli kırıcı ile kırılıp, yine aynı marka karbid çanaklı öğütücü de ögütülerek, 2 mm çapındaki (10 mesh) elekten geçirilip elenmiştir. GEC AVERY marka hassas terazi ile $10 \mathrm{~g}$ numune tartılarak bir erlene alınıp ve tartılan örnek $50 \mathrm{~mL} 1 \mathrm{M} \mathrm{NaOH}$ ile Clifton marka çalkalayıcı ve Nüve MK 218 marka karıştırıcı yardımı ile bir gece boyunca karıştırılarak ekstraksiyonu yapılmıştır. Daha sonra karışım 50 mL'lik 4 adet santrifüj tüpüne bölünerek karışım 30 dakika 10000 rpm'de SİGMA 6K15 marka santrifüjde santrifüjlenmiştir. Birinci süzüntüler 
ve çökeltiler birbirlerinden ayrılıp, ilk süzüntüler koruyucu bir kap içerisinde birleştirilerek santrifüjlenen 4 ayrı tüpteki çökeltiler aynı erlende birleştirilmiştir. Daha sonra bu erlende toplanan çökelti için 2. ve 3. seferde de aynı işlemler tekrarlanmış ve ikinci ve üçüncü süzüntüler daha önceki süzüntülerin bulunduğu kaba alınarak işlem tamamlanmıştır. Bu analizler C.Ü. Jeoloji Mühendisliği Petrol Jeoloji laboratuar'ında ve C.Ü. Biyoloji Bölümü Hidrobiyoloji laboratuar'ında yapılmıştır.

\section{Hümik asidin yıkanması}

İşlem süreci; toplanılan süzüntü $20 \mathrm{ml}$ konsantre $\% 37$ lik HCI ile muamele edilerek 6 saat karıştırıcıda bırakıldı. Karışım 20 mL'lik santrifüj tüplerine yine 8 ayrı parçaya bölünerek 30 dakika 10000 rpm'de santrifüjlendi. Hümik asit çöktürüldü. Süzüntüler (Fülvik Asit) ayrı bir beherde toplandı. Çökeltiler (Hümik asit) yıkama yapılmak için santrifüjlemeden sonra çöken hümik asitler $1 \mathrm{M} \mathrm{NaOH}$ çözeltisinin $20 \mathrm{~mL}$ 'si ile çözüldü ve saf su ile $200 \mathrm{~mL}$ 'ye tamamland1. $3 \mathrm{~mL}$ konsantre \%37'lik HCI eklendi ve yarım saat daha karıştırıldı. 30 dakika 10000 rpm'de santrifüjlendi. Birinci süzüntü ve çökelti birbirlerinden ayrıldı.

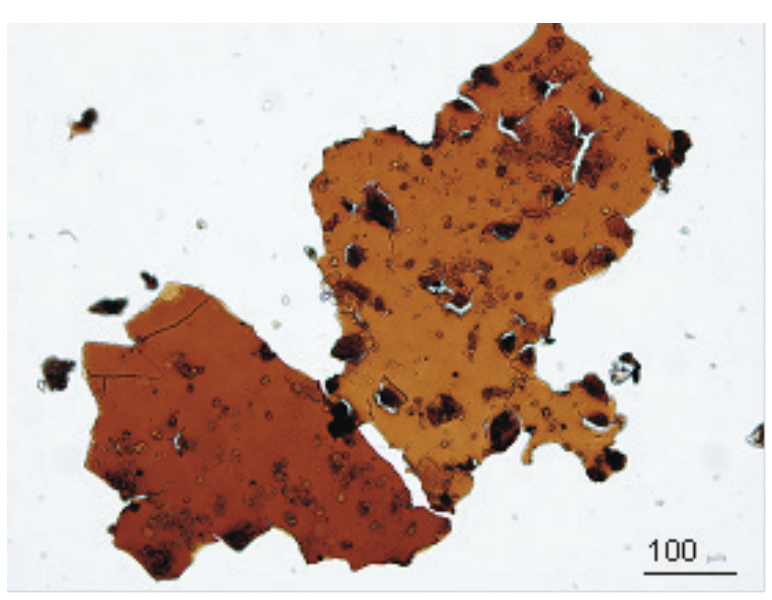

(a)
Çökelti bir erlene alınarak $10 \mathrm{~mL} 1 \mathrm{M} \mathrm{NaOH}$ çözeltisi ile çözülerek, saf su ile $200 \mathrm{~mL}$ ye tamamlandi. $1.5 \mathrm{~mL}$ konsantre \% 37'lik HCI eklendi ve 30 dakika 10000 rpm'de santrifüjlendi. İkinci süzüntü ve çökelti birbirlerinden ayrıldı. Çökelti bir erlene alındı. $80 \mathrm{~mL}$ saf su ve 10 damla \%37 lik konsantre HCI ilave edilmiş çözelti ile yıkand1. 30 dakika 10000 rpm'de santrifüjlendi. Üçüncü süzüntü ve çökelti birbirlerinden ayrıldı. Son yıkamadan sonra çöken madde (hümik asit) Philip Haris Pastor firınında kurutularak tartıldı (C.Ü. Biyoloji Bölümü, Hidrobiyoloji laboratuarı).

\section{Bitümlü şeyllerde pH Ölçümü}

Öğütülmüş $10 \mathrm{~g}$ numune 10 (2 mm) mesh elek ile elenerek bir beher içerisinde $30 \mathrm{~mL}$ saf su ile muamele edilip, 20 dakika karıştırıcıda karıştırıldı. 3-4 saat bekletildikten sonra $\mathrm{pH}$ ölçümü gerçekleştirildi.

\section{BULGULAR}

Deneysel çalışmalar sonucunda elde edilen hümik asitin, Olypus Bx51 mikroskopundaki görünümü Şekil 5'te görülmektedir.

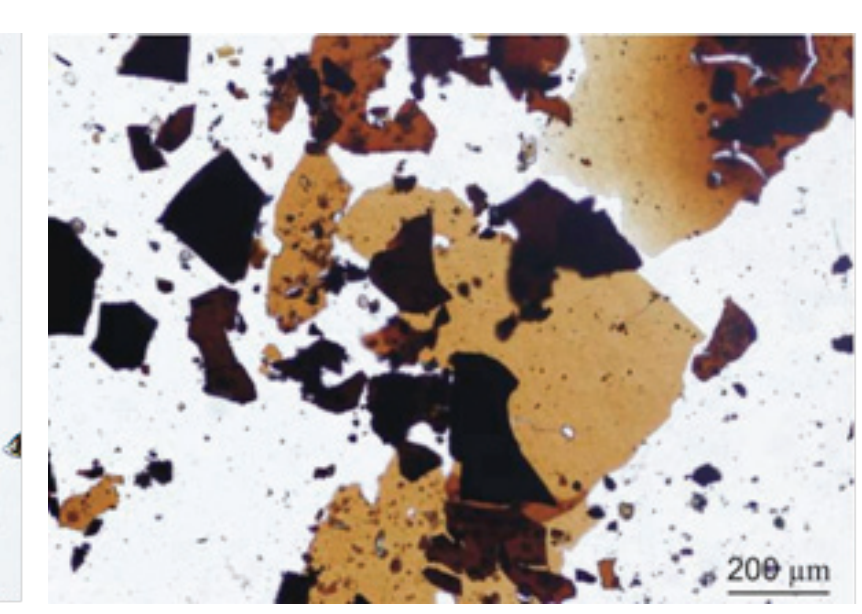

(b)

Şekil 5. Hümik asitin Olympus Bx51 mikroskop görüntüsü.

Figure 5. Microscopic image (Olympus Bx51) of humic acid. 
Başlangıçta $10 \mathrm{~g}$ bitümlü şeyl numunesi kullanılmış olup, analiz sonucunda $9.05 \mathrm{~g}$ örnek kalmıştır (\% 90.5 kalan bitümlü şeyl). Toplam hümik ve fülvik asitlerin miktarı için ise başlangıçta $10 \mathrm{~g}$ bitümlü şeyl numunesi kullanılmıştır. $0.95 \mathrm{~g}$ hümik ve fülvik asit miktarı belirlenmiş olup \% 9.5 Hümik asit + Fülvik asit yüzdesi olduğu belirlenmiştir.

Hümik asit miktarı $0.487 \mathrm{~g}$ olup, Fülvik asit miktarı ise 0.463 gramdır. Hümik asit yüzdesi $\% 4.87$ ve Fülvik asit yüzdesi ise \% 4.63' dir. Hümik Asit/ Fülvik Asit oranı ise 1.05 olarak hesaplanmıştır.

Humusta $\mathrm{pH}$ ölçümü sonucunda ise bitümlü şeylin pH'1 7.79, saf suyun pH'1 ise 5.78 olarak bulunmuştur.

\section{SONUÇLAR}

Bitki ve hayvansal organizmalara ait kalıntılarının farklı jeolojik zamanlar ve kimyasal süreçler geçirmesi sonucu oluşan bitümlü şeyller, dünyanın çeşitli bölgelerinde olduğu gibi ülkemizde de yaygın olarak bulunmaktadır. Ülkemizdeki bitümlü şeyl yatakları çoğunlukla Batı ve Orta Anadolu da yer almakta ve ortalama 1sıl değeri $1000 \mathrm{kcal} / \mathrm{kg}$ dolayında veya bunun altında kalmaktadır. Bileşimlerinde kül oranları oldukça yüksektir. Bitümlü şeyllerden petrol üretimi teknik olarak uygulanabilir olmasına karşılık ekonomikliği tartışmalıdır. Zira bitümlü şeylin \%10-15'lik kısmı ancak enerjiye dönüştürülebilir niteliktedir. Bu çalışmada bitümlü şeylerin organik gübre olarak kullanılması için hümik asit miktarı elde etmek amaçlanmıştır. 10 gramlık numuneden $\% 9.5$ Hümik asit ve Fülvik asit elde edilmiş, bu oranın \% 4.87 Hümik asit ve \% 4.63 oranında ise Fülvik asit olduğu belirlenmiştir.

Bir diğer önemli konu ise toprak ve bitki etkileşiminin önemli bir parametresi olan toprak çözeltisinin pH' 1 dır. Ülkemizin asidik özellikteki topraklarının pH' 'nı artırmak için bazik yönden zengin bitümlü şeylerin kullanılması uygun ve ekonomik bulunmaktadır. Düzağaç bitümlerini pH'1 7.79 olarak belirlenmiş olup, bu değer asidik topraklarımızın $\mathrm{pH}$ 'ının dengelenmesine yardımc olacaktır.

Ülkemizde var olan ancak enerji kaynağ1 olarak kullanımı ekonomik olmayan bitümlü şeyllerin organik gübre (Hümik Asit) olarak kullanılmasının ekonomik açıdan ve topraklarımızın 1slahı ve geleceği için büyük önem taşıdığı sonucuna varılmıştır.

\section{EXTENDED SUMMARY}

Bituminous shale in our country takes second place in terms of reserve, when compared the fossil energy resources such as coal, petroleum and natural gas and for this reason, it appears that they have an important value for the country economy. One of the biggest problems in our country, like in all over the world, is to meet the energy demand. Although lignite and coal from the most important fossil fuels having energy potential in our country have been considered important until today, it is not possible to say this for the bituminous shale. According to many scientific studies carried out in recent years, bituminous shale can be used both energy resource and different areas. One of these areas is the efforts to increase agricultural productivity. In the vast majority in our country's agricultural lands, due to below $1 \%$ of organic matter amount, there is a need for organic matter additives such as fertilizers to obtain efficient and high quality products. In this study, it has been tried to assess the potential of shale to increase the efficiency of soils, rather than as an energy source. In this context, possibility of use of Düzăgaç (Kozan-Adana) bituminous shale as a soil conditioner (compost-humic acid) has been investigated.

At the beginnig of the investigation, in the result of the analysis of $10 \mathrm{~g}$ of butiminous shale, it has been determined that there is $\% 9.5$ humic acid + fulvic acid. Amount of humic acid is 0.487 
$g$, while this value is 0.463 for fulvic acid. The percentages for humic and fulvic acid are \% 4.87 and $\% 4.63$, respectively. The ratio of humic acid to fulvic acid has found to be 1.05). pH of Düzăgaç bitumen was defined as 7.79 and this value will help our acidic soils to be balanced in terms of $p H$. In this study, it was concluded that the use of bituminous shale, which has not economic value as an energy source in our country, as compost (humic acid) is crucial to economical ways and our soil's reclamation and future.

\section{DEĞİNILEN BELGELER}

Ayhan, A., 1988, 1/100.000 ölçekli açınsama nitelikli Türkiye jeoloji haritaları serisi, Kozan- J21 paftası, MTA yayınları, Ankara.

Ballice, L., Yüksel, M., Sağlam, M. ve Hanoğlu, C., 1995. Mevcut enerji ve kimyasal hammadde kaynakları arasında bitümlü şistlerin yeri ve önemi. Ekoloji Dergisi, 14; 9 - 13.

Calemma, V. ve Rausa, R., 1988. Process for the production of regenerated humic acids from coal. US Patent 4.788.360.

Çolakoğlu, H., 1996. Organo-mineral Gübre Üretimine Yeni Yaklasımlar. Turkish Journal of Agriculture and Forestry, 20, s: 25-28. Özel Sayı Tübitak.

Dağlığlu, C., $\quad 1988 . \quad$ Kozan-Feke-Saimbeyli Tufanbeyli (Adana ilçeleri)-Sarız (Kayseri) ilçesi Dolayının Demir Cevherleşmeleri Prospeksiyonu Jeoloji Raporu; MTA Derleme No: 9215, 102 s. (yayınlanmamış).

Dağlıŏglu, C., 1990. T.D.Ç.A Genel Müdürlüğü adına Adana-Feke-Mansurlu Çevresinde AR:1704, AR:1544, AR:1660, AR:1662 Ruhsat Alanlarında Yapılan Etüt ve Arama Çalışmaları Jeoloji Raporu; MTA Derleme No: 8910 (yayınlanmamış).

Dekker, J. ve Cronje, I., 1991. Recovery of humic acids. US Patent 5.004.831.

Demirtaşlı, E., 1967. Pınarbaşı-Sarız-Mağara civarının jeoloji raporu; MTA Enst. Raporu, Rap. No: 1935,
129 s. (yayınlanmamıs).

Depel, G., 2000. Düşük Değerli Linyitin Tarımda Kullanılma Olanağı. Yüksek Lisans Tezi, Ankara Üniversitesi Fen Bilimleri Enstitüsü, Ankara, 54s.

Detroit, W. ve Lebo, Jr. 1997, Production of acid soluble humates. US Patent 5.663.425.

DPT, 2001. 8. Beş Yıllık Kalkınma Planı, ÖIKK Raporu, $11-50$.

EASAC Report, 2007. A Study on the EU Oil Shale Industry-Viewed in the Light Oil the Estonian Experience, A Report by EASAC to the Committee on Industry, Research and Energy of the EU Parliament.

Eyüpoğlu, F., 1999. Türkiye Topraklarının Verimlilik Durumu. Toprak ve Gübre Araştırma Enstitüsü Yayınları, Genel Yayın No: 220, Ankara.

FAO, 2009. Resource STAT-Fertilizer. Food and Agriculture Organization of the United Nations. http://faostat.fao.org/site/575/Desktop

Francioso, O., Ciavatta, C., Montecchio, D., Tugnoli, V., Sanchez-Cortes, S. and Gessa, C., 2003. Quantitative estimation of peat, brown coal and lignite humic acids using chemical paremeters, 1H-NMR and DTAanalyses. Bioresource Technology, 88; 189-195.

Grabowska, E. L. ve Gryglewicz, G., 2005. Adsorption of lignite-derived humic acids on coal-based mesoporous activated carbons. Journel of Colloid and Interface Science 284; 416-423.

Hayes, M.H.B., MacCarthy, P., Malcolm, R.L. ve Swift, R.S. (Eds.)., 1989. Humic Substances H: In Search of Structures, Wiley, New York.

Ketin, A., 1966. Anadolu'nun tektonik birlikleri; M.T.A Dergisi, 6, 20-34.

Kim, H.T., 2003. Humic Matter in Soil and the Environment ; c. 7, p: 31.

Kural, O., 1978. Türkiye Linyitlerinde Humik Asit Dağılımının İncelenmesi. İTÜ Maden Fakültesi. Doktora Tezi, 99 s, (Yayımlanmamış).

Kural, O., 1998. Kömür Özellikleri, Teknolojisi ve 
Çevre İliskileri. İstanbul Teknik Üniversitesi, Maden Fakültesi Kimya Mühendisliği Bölümü, İstanbul, 55; 117-127.

Kök, M.V., 2006. Oil Shale Resources in Turkey, Oil Shale, 23 (3) 209-210.

Güleç, K. ve Önen, A., 1993. Turkish oil shales: reserves, characterization and utilization, Proceedings of the 1992 Eastern Oil Shale Symposium, University of Kentucky, Institute for Mining and Minerals Research, Lexington, USA, pp. 12-24.

Laherrere, J., 2005. Review of Oil Shale Data, www. hubbertpeak.com/laherrere/ OilShale Review.pdf.

Lehtonen, K., Hanninen, K. and Ketola, M., 2001. Structurally bound lipids in peat humic acids. Organic Geochemistry, 32; 33-43.

Lguriate, A., Ait Baddi, G., El Mousadik, A., Gilard, V., Revel, J.C. and Hafidi, M., 2005. Analysis of humic acids from aerated and non- aerated urban landfill composts. Internetional biodeterioration \& biodegradation, 56; 8-16.

Metin, S., 1984. Doğu Toroslar'da Derebaşı (Develi), Armutalan ve Gedikli (Saimbeyli) Köyleri Arasının Jeolojisi; A.Ü. Müh. Mim. Fak. Yerbilimleri Dergisi., 4, 1-2, 45-66.

Metin, S., Papak, I. ve Keskin, H., 1982. TufanbeyliSarız ve Göksün Saimbeyli Arasının Jeolojisi, MTA Rap., Ankara, No: 7219 (yayımlanmamış).

Özgül, N., 1971. Orta Toroslar'ın kuzey kesiminin yapısal gelişiminde blok hareketlerinin önemi; Türkiye Jeol. Kur. Bült., 14, 75-87.

Özgül, N., Metin, S., Göger, E., Bingöl, A., Baydar, O. ve Erdoğan, B., 1973. Tufanbeyli dolayının (Doğu Toroslar, Adana) Kambriyen-Tersiyer kayaları; Türkiye Jeoloji Kurumu Bülteni, 16, 39-52.

Özgül, N., 1976. Torosların Bazı Temel Jeoloji Özellikleri; TJK Bülteni, 19, 1, 65-78.

Özgül, N. ve Kozlu, H., 2002. Kozan-Feke (Doğu Toroslar) Yöresinin Stratigrafisi ve Yapısal Konumu ile İlgili Bulgular; Türkiye Petrol Jeologları Derneği Bülteni, 14, 1, 1-36.
Özgül, N., 2006. Toroslar'ın Paleozoyik Yaşta Bazı Kaya Stratigrafi Birimleri. Stratigrafi Komitesi 6. Çalıştay1 (Toros Kuşağı ve Güneydogu Anadolu Bölgesi Prekambriyen-Paleozoyik Kaya Birimlerinin Litostratigrafi Adlamaları); Bildiri Özleri, 1-8, Ankara.

Probstein, R.F. ve Hicks, R.E., 1982, Synthetic Fuels, Mc Graw Hill Chemical Engineering Series, 322373.

Senn, T. L. And Kingman, A. R., 1973. "A review of Humus and Humic Acids." Clemson University, Dept of Horticulture, Research Series No. 145.

Skhonde, M.P. Herod, A.A., Van der Walt, T.J., Tsatsi, W.L. ve Mokoena, K., 2006. The effect of thermal treatment on the compositional structure of humic acids extracted from South African bituminous coal. International Journal of Mineral Processing, 01950; $1-7$.

Şengüler, İ. 1985, Bitümlü şeylden yararlanma. Yeryuvar1 ve insan, 10, 4, 59-63.

Şengüler, İ., 1994. Bitümlü şeyl. Türkiye Enerji Bülteni, TMMOB Jeoloji Mühendisleri Odası Yayını, 1,1, 21-26.

Şengüler, İ., 2001. Türkiye bitümlü şeyllerinin GAP bölgesinde toprak güçlendirici olarak kullanılma imkanlarının araştırılması ve geliştirilmesi. MTA Genel Müdürlüğü Enerji Hammadde Etüt ve Arama Daire Başkanlığı, 21 s., Ankara.

Şengüler, İ., 2007. Asfaltit ve Bitümlü Şeylin Türkiye'deki Potansiyeli ve Enerji Değeri, TMMOB Türkiye VI. Enerji SempozyumuKüresel Enerji Politikaları, Ankara.

Taban, S. ve Turan, M.A., 2012. Tarımda Gübre Çevre İlişkileri.TarımTürk, 34: 10-14.

Tissot, B.P., ve Welte, D.H., 1984. Petroleum Formation and Occurrence: Springer-Verlag. Berlin.

Toraman, Ö.Y. ve Uçurum, M., 2009. Alternatif Fosil Enerji Kaynağı: Bitümlü Şeyl, TÜBAV Bilim Dergisi 2(1), 37-46.

USA Department of Energy, 2004. Strategic 
Significance of America's Oil Shale Resource, Vol.II, Section 2.1.

Ünalan, G., 2003. Türkiye Enerji Kaynaklarının Genel Değerlendirmesi, Jeoloji Mühendisliği Dergisi, 27 (1).

Valdrighi, M. M., Pera, A., Agnolucci, M., Frassinitti, S., Lunardi, D. and Vallini, G., 1996. Effect of compost-derived humic acids on vegetable biomass production and microbial growth within a plant (Cichorium intybus)-soil system: a comparative study.Agriculture Ecosystems \& Environment, 58; 133-144.

Vogel, E., Geßner, R., Hayes, M.H.B. ve Kiefer, W., 1999. Characterisation of humic acid by means of SERS, Journal of Molecular Structure vol. 482483, p. 195-199.

World Energy Council (WEC), Survey of Energy Resources, 21, ISBN 0946121265, Retrieved on 2007-11-13.

Yapıc1, N. ve Anıl, M., 2007. Düzağaç Kuvarsit Yatağının (Kozan-Adana) Cam Sanayinde Kullanılabilirliğinin Araştırılması. Ç.Ü. Müh. Mim. Fak. Dergisi, Cilt 22, Say1, 2 .309-323.

Makale Geliş Tarihi : 14 Ekim 2014

Kabul Tarihi : 14 Nisan 2015

Received

: 14 October 2014

Accepted : 14 April 2015 